\title{
openheart Analysis of weekend effect on 30-day mortality among patients with acute myocardial infarction
}

\author{
Rebecca Noad, ${ }^{1}$ Michael Stevenson, ${ }^{2}$ Niall A Herity ${ }^{1}$
}

To cite: Noad R, Stevenson M, Herity NA. Analysis of weekend effect on 30-day mortality among patients with acute myocardial infarction. Open Heart 2017;4. doi:10.1136/ openhrt-2016-000504

- Prepublication history is available. To view please visit the journal (http://dx.doi.org/10. 1136/openhrt-2016-000504).

Received 26 July 2016 Revised 13 September 2016 Accepted 20 September 2016

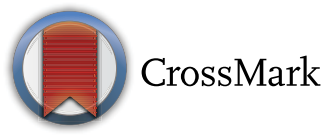

'Department of Cardiology, Belfast HSC Trust, Belfast, Northern Ireland ${ }^{2}$ Centre for Public Health, Queen's University Belfast, Belfast, Northern Ireland

Correspondence to Dr Niall A Herity; Niall.Herity@ belfasttrust.hscni.net

\section{ABSTRACT}

Objectives Several publications have demonstrated increased 30-day mortality in patients admitted on Saturdays or Sundays compared with weekdays. We sought to determine whether this was true for two different cohorts of patients admitted with acute myocardial infarction (MI).

Methods and results Thirty-day mortality data were obtained for 3757 patients who had been admitted to the Belfast Health and Social Care Trust with acute MI between 2009 and 2015. They were subdivided into those presenting with ST elevation MI $(n=2240)$ and non-ST elevation MI ( $n=1517)$. We observed no excess 30-day mortality in those admitted over weekends.

Conclusion Excess mortality in patients admitted at weekends is not a universal finding. This may mean that that there are patient subgroups with proportionately greater weekend hazard and points to the need for more detailed understanding of the weekend effect.

\section{INTRODUCTION}

In 2012, Freemantle et al. demonstrated that patients admitted to hospitals in England had higher 30-day mortality if admitted over a weekend compared with on a weekday. ${ }^{1}$ This was true for both non-emergency admissions and selected emergency admissions.

A more recent analysis by the same group ${ }^{2}$ confirmed what has come to be known as the weekend effect: among all patients admitted to hospitals in England in 2013-2014, 30-day mortality was higher in patients admitted over a weekend. The emergency admissions subset has been released subsequently and demonstrates higher 30-day mortality in patients admitted on Saturdays and Sundays. ${ }^{3}$ This is an international phenomenon and has been observed in many healthcare systems. ${ }^{45}$

We sought to test the hypothesis that there is excess weekend mortality in patients admitted with acute MI. We studied two cohorts of patients: a group with ST elevation myocardial infarction (STEMI) and a group with non-ST elevation myocardial infarction (NSTEMI). They were considered separately, because they are managed by two different medical processes: STEMI patients by a $24 / 7$

\section{KEY QUESTIONS}

What is already known on this subject?

- Several publications have demonstrated increased 30-day mortality in patients admitted on Saturdays or Sundays compared with weekdays.

What might this study add?

- We observed no excess 30-day mortality in patients admitted with acute myocardial infarction over weekends.

How might this impact on clinical practice?

- Excess mortality with weekend emergency admissions is not a universal finding.

consultant-delivered service and NSTEMI patients by more traditional clinical methods, including reduced medical staffing levels at weekends.

\section{METHODS}

\section{Study design}

Demographic and clinical data were collected using standardised and validated data collection sheets as part of the MINAP (Myocardial Infarction National Audit Project) database. These contained information on age, gender, cardiovascular risk factors, diagnosis, and date and time of admission. This is a national database, and all patient information was fully anonymised and stored securely in accordance with Good Clinical Practice. Linked 30 day mortality data encompassing deaths in and outside hospital were obtained from the Honest Broker Service for Northern Ireland. Mortality data were available for the entire cohort.

\section{Patient population}

Patients admitted to the Belfast Health and Social Care Trust with a diagnosis of acute MI between April 2009 and September 2015 were included in this study. The Belfast Trust since 2009 has operated a primary percutaneous 


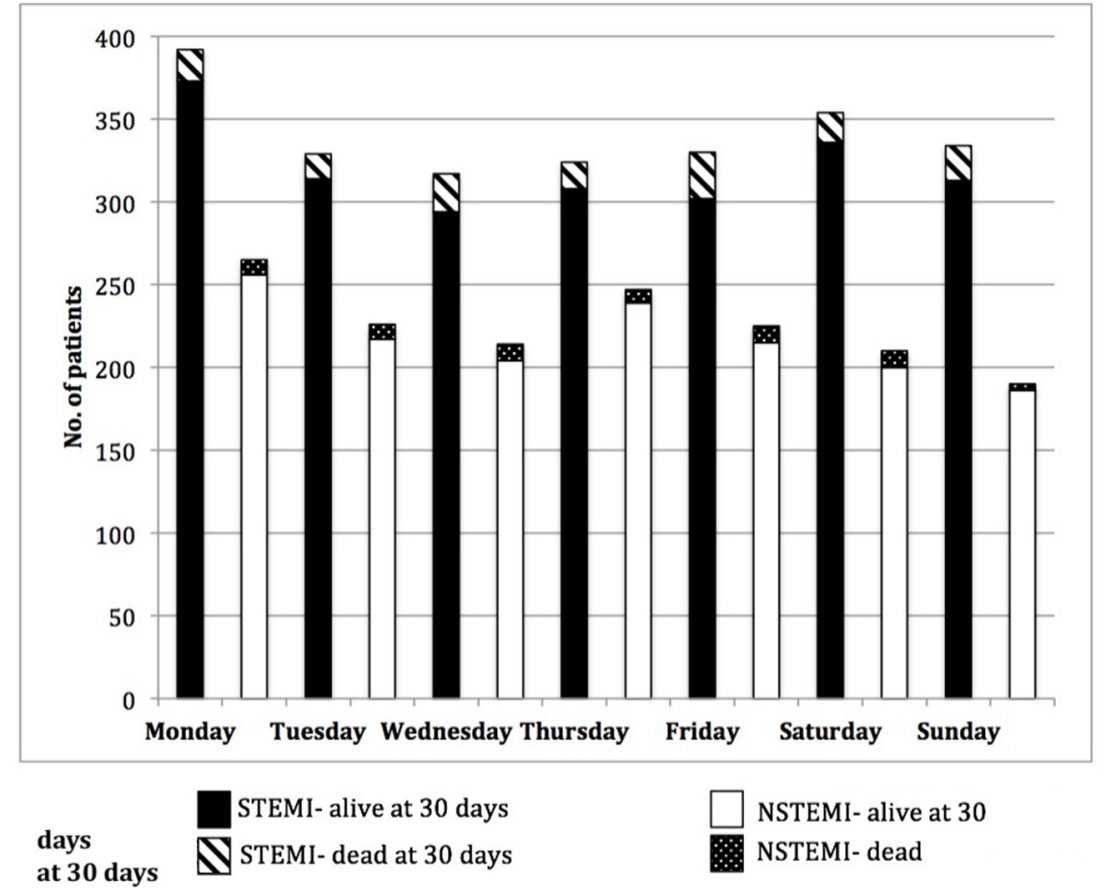

Figure 1 Day of admission of 3757 patients admitted with STEMI or NSTEMI, subdivided by 30-day survival status. NSTEMI, non-ST elevation myocardial infarction; STEMI, ST elevation myocardial infarction.

coronary intervention (PPCI) service $24 / 7$ for all patients presenting with STEMI. The service delivery arrangement for these patients is that they are identified by an ECG at the time of presentation. If this meets criteria for PPCI, then a consultant cardiologist and team are called to perform emergency angiography within $30 \mathrm{~min}$. The service delivery arrangement for NSTEMI's is different. These patients are managed with initial medical stabilisation at ward level, followed by an inpatient angiogram, ideally within 72 hours of admission. For the purposes of this study, the ICD-10 (International Statistical Classification of Diseases and Related Health Problems 10th Revision) definition of MIs were used. In keeping with other studies in this area, an admission on Monday-Friday was considered to be 'weekday', regardless of the time of admission, and admissions on Saturday and Sunday were classified as 'weekend'.

\section{End point}

The primary end point was 30-day mortality analysed by day of admission.

\section{Statistical analysis}

Categorical variables are presented as percentages and comparison between groups (all-weekday vs all-weekend admissions) made using the $\chi^{2}$ test. Continuous variables are presented as mean $\pm \mathrm{SD}$, and comparison between groups made used independent-samples t-test. Additionally, a Cox proportional-hazards model was constructed to compare HRs for 30-day mortality by day of admission, comparing every other day with Wednesday and correcting for recognised significant covariates. Analysis was performed using IBM SPSS Statistics, V.21.0., Armonk, New York, USA.

\section{RESULTS}

In total, 3757 patients were included: 2240 with STEMI and 1517 with NSTEMI to the Belfast Health and Social Care Trust between April 2009 and September 2015. Day of admission was evenly spread across the week among all patients and among those who died within 30 days, as demonstrated by the histogram (figure 1).

Data were available on the following demographic details and cardiovascular risk factors: age, gender, previous MI, left ventricular ejection fraction, cardiac arrest, hypertension, hypercholesterolaemia, peripheral vascular disease, cerebrovascular disease, chronic obstructive pulmonary disease, chronic kidney disease, smoking status and diabetes. Weekend versus weekday prevalence for each of these is displayed in table 1, with comparison statistics, for both STEMI and NSTEMI. There was no significant difference in presenting risk factors between groups, with the exception of age; those presenting with NSTEMIs at weekends were significantly older $(67.7 \pm 13.0$ vs $70.2 \pm 13.1, \mathrm{p}=0.01)$. In the entire cohort, 30-day mortality was $5.32 \%(6.25 \%$ among patients with STEMI and $3.96 \%$ in patients with NSTEMI). We observed no difference in 30-day mortality between those admitted at weekends and those admitted on weekdays (table 1).

The Cox proportional-hazards model constructed HRs for 30-day mortality associated with each day of admission compared with Wednesday. All available clinical and demographic variables, which are listed above, were 
Health care delivery, economics and global health care

Table 1 Baseline characteristics among 3757 patients admitted with acute MI by day of admission and type of MI

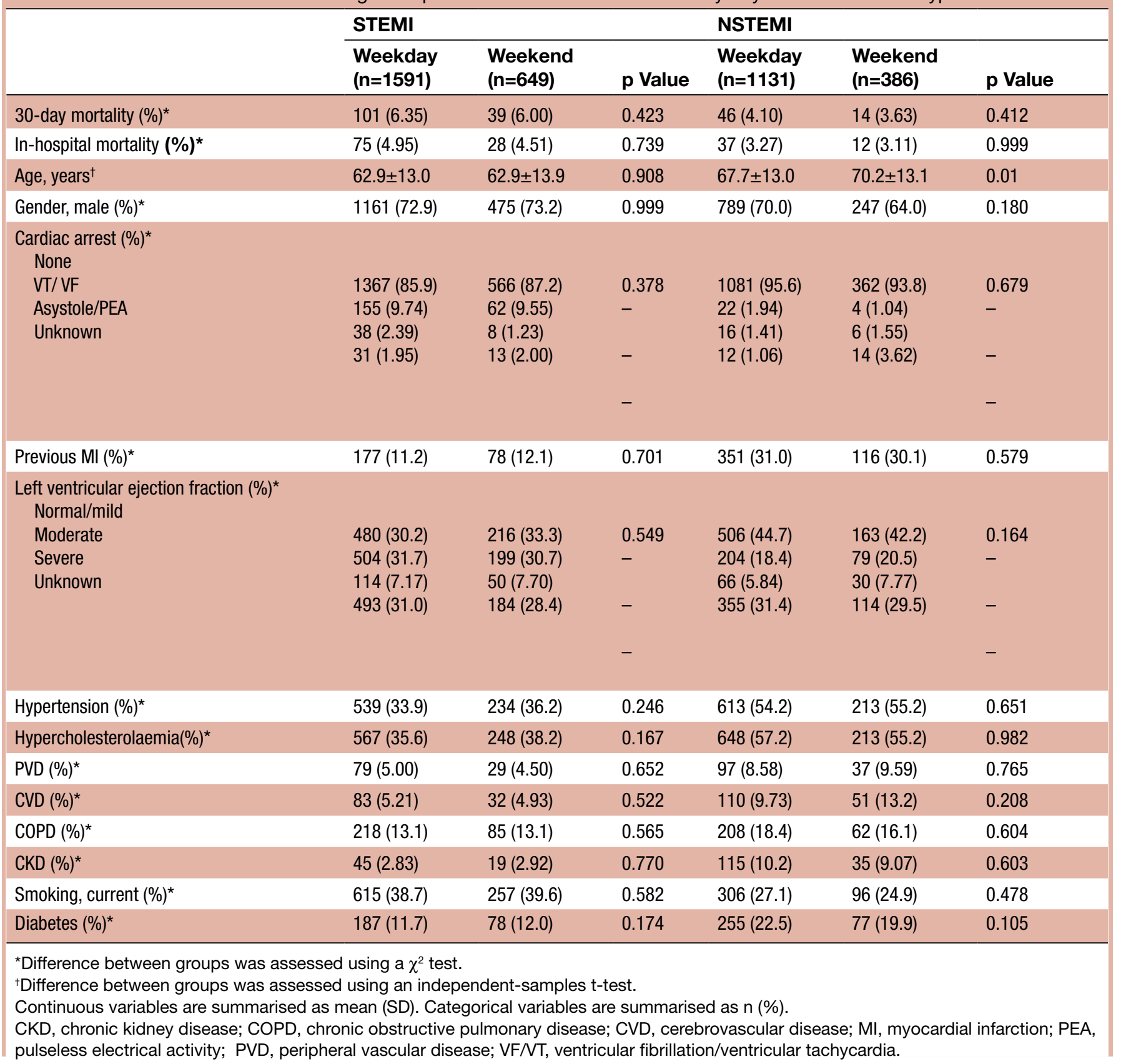

included initially in the model. Following this preliminary analysis, risk factors that were revealed to influence mortality, which are listed below, were included in the final model. Within the model, analysis of three clinical covariates revealed no significant excess hazard for the type of infarction (STEMI vs NSTEMI) (HR 1.03; $95 \%$ CI 0.87 to 1.23 ) but significant excess hazards for increasing age (HR 1.05; $95 \%$ CI 1.04 to 1.06 ) and female gender (HR 1.43; 95\% CI 1.20 to 1.70 ). Following adjustment for these three covariates, there was no significant excess hazard for any day of the week compared with Wednesday (table 2).

To increase the overall power of this study, a further Cox proportional-hazards model was constructed comparing weekdays versus weekends as opposed to individual days (table 3). No significant effect on mortality was found using this variable (weekend admission HR 0.998; 95\% CI 0.8236 to 1.203 ). Age, gender and type of MI were also included in this model as above.

\section{DISCUSSION}

In this study, we observed no excess 30-day mortality hazard in patients admitted with acute MI over weekends, indicating that excess weekend mortality is not a universal phenomenon. This suggests that there may be other patient groups with proportionately greater weekend 
Table 2 Cox proportional HRs (95\% Cls) comparing 30-day mortality hazard associated with each day of admission compared with Wednesday among 3757 patients admitted with acute myocardial infarction (MI) following adjustment for type of infarction, age and gender

\begin{tabular}{|c|c|c|c|c|c|c|}
\hline & \multicolumn{6}{|c|}{ 30-day mortality } \\
\hline & $\begin{array}{l}\text { Sunday vs } \\
\text { Wednesday }\end{array}$ & $\begin{array}{l}\text { Monday vs } \\
\text { Wednesday }\end{array}$ & $\begin{array}{l}\text { Tuesday vs } \\
\text { Wednesday }\end{array}$ & $\begin{array}{l}\text { Thursday vs } \\
\text { Wednesday }\end{array}$ & Friday vs Wednesday & $\begin{array}{l}\text { Saturday vs } \\
\text { Wednesday }\end{array}$ \\
\hline $\begin{array}{l}\text { Patients with Ml } \\
(\mathrm{n}=3757)\end{array}$ & $\begin{array}{l}0.997 \\
\text { (0.722 to } 1.375)\end{array}$ & $\begin{array}{l}1.001 \\
\text { (0.735 to } 1.362)\end{array}$ & $\begin{array}{l}0.856 \\
\text { (0.616 to } 1.188)\end{array}$ & $\begin{array}{l}0.880 \\
\text { (0.634 to } 1.220)\end{array}$ & $\begin{array}{l}0.962 \\
\text { (0.701 to } 1.319)\end{array}$ & $\begin{array}{l}0.883 \\
\text { (0.640 to } 1.139)\end{array}$ \\
\hline
\end{tabular}

hazard, pointing to the need for a more detailed understanding of the weekend effect.

Higher mortality in patients admitted at weekends has been observed in many different patient groups over several years in many different countries, although the pattern differs between different healthcare systems. ${ }^{67}$ It has been documented in patients admitted as emergencies and in patients admitted electively. ${ }^{128}$ Indeed, while emergency patients experience higher mortality than elective patients, the weekend hazard is proportionately greater in patients admitted electively. ${ }^{8}$

Mechanisms that might explain higher mortality in weekend admissions have been summarised as the 'sicker weekend patient' hypothesis or the quality-of-care hypothesis ; a combination of the two is another possibility. Most authors in the field have concluded that the current evidence base does not allow exclusion of either hypothesis, and hence, strategies to address the weekend effect should take account of this evidence gap.

Studies in acute MI can give particular insight into the weekend effect, especially into the impact of out-of-hours staffing levels on mortality. It is a common emergency condition presenting evenly across the week. Diagnostic tests are sensitive and specific, and so, the diagnosis is typically accurate. Patients are managed in single-specialty wards according to well-defined clinical pathways. Most importantly, the same pathological condition presents in a spectrum of different ways, and the mode of presentation will determine the clinical pathway that is followed. Those with STEMI are treated by rapid-response consultant-led teams, who deliver expert care

Table 3 Cox proportional HRs (95\% Cls) comparing 30-day mortality hazard associated with weekday versus weekend admission among 3757 patients admitted with acute $\mathrm{Ml}$ following adjustment for type of infarction, age and gender

\begin{tabular}{lll}
\hline & 30-day mortality & \\
\cline { 2 - 3 } & Covariate & Exp (B) (95\% Cl) \\
\hline $\begin{array}{l}\text { Patients } \\
\text { with MI } \\
(n=3757)\end{array}$ & Type of MI & $1.031(0.867$ to 1.225) \\
& (STEMI vs NSTEMI) & \\
& Weekend & $0.996(0.826$ to 1.203$)$ \\
& Age & $1.048(1.040$ to 1.055$)$ \\
& Gender & $1.428(1.199$ to 1.701$)$ \\
\hline
\end{tabular}

MI, myocardial infarction; NSTEMI, non-ST elevation myocardial

infarction; STEMI, ST elevation myocardial infarction. immediately from the time of admission, and the level of care is the same 24 hours a day, 7 days a week. In contrast, patients with NSTEMI are treated by more traditional clinical pathways, which include reduced levels of medical staffing over weekends. Hence, if the 'weekend effect' is a consequence of varying medical staffing levels across the working week, it should be seen in patients with NSTEMI but not those with STEMI. This is not what we observed.

Previous studies of patients with acute MI have found higher mortality in those admitted at weekends. Some reflect observations made many years ago, ${ }^{9}$ but others reflect contemporary practice. ${ }^{1} 1011$ The absence of a weekend effect in our patients with STEMI is in keeping with recent observations of consistent mortality across the week for STEMI patients treated by PPCI. ${ }^{12}$ Less intuitive is the observation of no excess mortality in our patients admitted with NSTEMI at weekends. One explanation is that the number of deaths in the NSTEMI population was too small to allow us to detect a true difference in mortality between weekdays and weekends. Second, while NSTEMI patients are managed by systems with reduced staffing levels at weekends, this does not translate into more deaths. Third, the institution of 24/7 PPCI services for patients with STEMI may have brought an unexpected benefit for patients with NSTEMI, that is, more robust recognition of higher risk patients and a lower threshold for out-of-hours intervention, including over weekends.

One of the limitations of our study is that it is retrospective and observational; this is the case for all publications in this field, as it is not possible to prospectively randomise patients with a life-threatening emergency condition by day of admission. Second, we have described observations from a single centre; while data from several thousand patients are included, the size of the cohorts studied is smaller than in many previous publications. In order to address this limitation we propose that our analysis should be repeated in the Myocardial Ischaemia National Audit Project (MINAP) database which collects comprehensive data on more than 80000 MI patients admitted annually across England, Wales and Northern Ireland. ${ }^{13}$ Finally, statutory holidays were not accounted for which may have led patients to be categorised as weekday admissions erroneously, and the clinical data available is not comprehensive which may be an additional confounding factor. 


\section{CONCLUSIONS}

We observed no excess 30-day mortality in patients admitted with acute MI over weekends indicating that excess weekend mortality is not a universal phenomenon. There may be patient subgroups with proportionately greater weekend hazard, pointing to the need for a more detailed understanding of the weekend effect.

Acknowledgements We are grateful for the contribution of Audrey Tomlin and Mary McGeough for MI data collection and the Honest Broker Service, Northern Ireland, for providing mortality data.Data sharing statement There are no additional unpublished data available for sharing

Contributors NAH designed the study plan, monitored data collection and drafted and revised the paper. He is a guarantor. RN designed the study plan, data collection tools, monitored data collection for the whole trial, assisted with statistical analysis and drafted and revised the paper. MS designed the statistical plan, performed the statistical analysis and helped with the revision of the paper.

Competing interests None declared.

Provenance and peer review Not commissioned; externally peer reviewed.

Open Access This is an Open Access article distributed in accordance with the Creative Commons Attribution Non Commercial (CC BY-NC 4.0) license, which permits others to distribute, remix, adapt, build upon this work non-commercially, and license their derivative works on different terms, provided the original work is properly cited and the use is non-commercial. See: http://creativecommons.org/ licenses/by-nc/4.0

(c) Article author(s) (or their employer(s) unless otherwise stated in the text of the article) 2017. All rights reserved. No commercial use is permitted unless otherwise expressly granted.

\section{REFERENCES}

1. Freemantle N, Richardson M, Wood J, et al. Weekend hospitalization and additional risk of death: an analysis of inpatient data. J R Soc Med 2012;105:74-84.
2. Freemantle N, Ray D, McNulty D, et al. Increased mortality associated with weekend hospital admission: a case for expanded seven day services? BMJ 2015;351:h4596.

3. Freemantle N. Supplementary data following rapid responses to 'Increased mortality associated with weekend hospital admission: a case for expanded seven day services?'. 2015. http://static.www. bmj.com/sites/default/files/response_attachments/2015/10/Figure\% 20271015.doc (accessed 8 Feb 2016).

4. Vest-Hansen B, Riis AH, Sørensen HT, et al. Out-of-hours and weekend admissions to Danish medical departments: admission rates and 30 -day mortality for 20 common medical conditions. BMJ Open 2015;5:e006731.

5. Sorita A, Ahmed A, Starr SR, et al. Off-hour presentation and outcomes in patients with acute myocardial infarction: systematic review and meta-analysis. BMJ 2014;348:f7393.

6. Bell CM, Redelmeier DA. Mortality among patients admitted to hospitals on weekends as compared with weekdays. N Engl J Med 2001;345:663-8.

7. Ruiz M, Bottle A, Aylin PP. The global Comparators project: international comparison of 30-day in-hospital mortality by day of the week. BMJ Qual Saf 2015;24:492-504.

8. Mohammed MA, Sidhu KS, Rudge G, et al. Weekend admission to hospital has a higher risk of death in the elective setting than in the emergency setting: a retrospective database study of national health service hospitals in England. BMC Health Serv Res 2012;12:87.

9. Kostis WJ, Demissie K, Marcella SW, et al; Myocardial Infarction Data Acquisition System (MIDAS 10) Study Group. Weekend versus weekday admission and mortality from myocardial infarction. $N$ Engl J Med 2007;356:1099-109.

10. Canadian institue for health information. weekend admissions and in-hospital mortality. https://secure.cihi.ca/free_products/Mortality Report_2014_en.pdf (accessed 8 Feb 2016).

11. Isogai $T$, Yasunaga $H$, Matsui $H$, et al. Effect of weekend admission for acute myocardial infarction on in-hospital mortality: a retrospective cohort study. Int J Cardiol 2015;179:315-20.

12. Noman A, Ahmed JM, Spyridopoulos I, et al. Mortality outcome of out-of-hours primary percutaneous coronary intervention in the current era. Eur Heart J 2012;33:3046-53.

13. NICOR. Annual Report 2014. https://www.ucl.ac.uk/nicor/audits/ minap/documents/annual_reports/minap-public-report-2014 (accessed 8 Feb 2016). 


\section{Correction: Analysis of weekend effect on 30-day mortality among patients with acute myocardial infarction}

Noad R, Stevenson M, Herity NA. Analysis of weekend effect on 30-day mortality among patients with acute myocardial infarction. Open Heart 2017;4:e000504.

Since this article was first published, errors have been identified in table 1. Some of the percentages for 30-day mortality and in-hospital mortality were calculated incorrectly. The correct table is below, and the corrected values are shown in bold.

Table 1 Baseline characteristics among 3757 patients admitted with acute MI by day of admission and type of MI

\begin{tabular}{|c|c|c|c|c|c|c|}
\hline & STEMI & & & NSTEMI & & \\
\hline & $\begin{array}{l}\text { Weekday } \\
(n=1591)\end{array}$ & $\begin{array}{l}\text { Weekend } \\
(n=649)\end{array}$ & $P$ value & $\begin{array}{l}\text { Weekday } \\
(n=1131)\end{array}$ & $\begin{array}{l}\text { Weekend } \\
(n=386)\end{array}$ & $P$ value \\
\hline 30 -day mortality $(\%)^{*}$ & $101(6.35)$ & $39(6.01)$ & 0.423 & $46(4.07)$ & $14(3.63)$ & 0.412 \\
\hline In-hospital mortality (\%) ${ }^{*}$ & $75(4.71)$ & $28(4.31)$ & 0.739 & $37(3.27)$ & $12(3.11)$ & 0.999 \\
\hline Age, years $†$ & $62.9 \pm 13.0$ & $62.9 \pm 13.9$ & 0.908 & $67.7 \pm 13.0$ & $70.2 \pm 13.1$ & 0.01 \\
\hline Gender, male $(\%)^{*}$ & $1161(72.9)$ & $475(73.2)$ & 0.999 & $789(70.0)$ & $247(64.0)$ & 0.180 \\
\hline Cardiac arrest $(\%)^{*}$ & & & & & & \\
\hline None & $1367(85.9)$ & $566(87.2)$ & 0.378 & $1081(95.6)$ & $362(93.8)$ & 0.679 \\
\hline VT/ VF & $155(9.74)$ & $62(9.55)$ & - & $22(1.94)$ & $4(1.04)$ & - \\
\hline Asystole/PEA & $38(2.39)$ & $8(1.23)$ & - & $16(1.41)$ & $6(1.55)$ & - \\
\hline Unknown & $31(1.95)$ & $13(2.00)$ & - & $12(1.06)$ & $14(3.62)$ & - \\
\hline Previous Ml $(\%)^{\star}$ & 177 (11.2) & 78 (12.1) & 0.701 & $351(31.0)$ & $116(30.1)$ & 0.579 \\
\hline Left ventricular ejection fractio & & & & & & \\
\hline Normal/mild & $480(30.2)$ & $216(33.3)$ & 0.549 & $506(44.7)$ & $163(42.2)$ & 0.164 \\
\hline Moderate & $504(31.7)$ & $199(30.7)$ & - & $204(18.4)$ & $79(20.5)$ & - \\
\hline Severe & $114(7.17)$ & $50(7.70)$ & - & $66(5.84)$ & $30(7.77)$ & - \\
\hline Unknown & $493(31.0)$ & $184(28.4)$ & - & $355(31.4)$ & $114(29.5)$ & - \\
\hline Hypertension $(\%)^{\star}$ & $539(33.9)$ & $234(36.2)$ & 0.246 & $613(54.2)$ & $213(55.2)$ & 0.651 \\
\hline Hypercholesterolaemia(\%)* & 567 (35.6) & $248(38.2)$ & 0.167 & $648(57.2)$ & $213(55.2)$ & 0.982 \\
\hline PVD $(\%)^{\star}$ & $79(5.00)$ & $29(4.50)$ & 0.652 & 97 (8.58) & $37(9.59)$ & 0.765 \\
\hline $\operatorname{CVD}(\%)^{*}$ & $83(5.21)$ & $32(4.93)$ & 0.522 & $110(9.73)$ & $51(13.2)$ & 0.208 \\
\hline $\operatorname{COPD}(\%)^{\star}$ & $218(13.1)$ & $85(13.1)$ & 0.565 & $208(18.4)$ & $62(16.1)$ & 0.604 \\
\hline $\operatorname{CKD}(\%)^{*}$ & $45(2.83)$ & $19(2.92)$ & 0.770 & $115(10.2)$ & $35(9.07)$ & 0.603 \\
\hline Smoking, current $(\%)^{*}$ & $615(38.7)$ & $257(39.6)$ & 0.582 & $306(27.1)$ & $96(24.9)$ & 0.478 \\
\hline Diabetes $(\%)^{*}$ & $187(11.7)$ & $78(12.0)$ & 0.174 & $255(22.5)$ & 77 (19.9) & 0.105 \\
\hline
\end{tabular}

*Difference between groups was assessed using a $\chi 2$ test.

†Difference between groups was assessed using an independent-samples t-test. Continuous variables are summarised as mean (SD). Categorical variables are summarised as $\mathrm{n}(\%)$.

CKD, chronic kidney disease; COPD, chronic obstructive pulmonary disease; CVD, cerebrovascular disease; MI, myocardial infarction; PEA, pulseless electrical activity; PVD, peripheral vascular disease; VF/ $\mathrm{VT}$, ventricular fibrillation/ventricular tachycardia.

(c) Author(s) (or their employer(s)) 2022. No commercial re-use. See rights and permissions. Published by BMJ.

Open Heart 2022;9:e000504corr1. doi:10.1136/openhrt-2016-000504corr1 